\title{
PENDIDIKAN BAGI ANAK TUNA GRAHITA (STUDI KASUS TUNAGRAHITA SEDANG DI SLB N PURWAKARTA)
}

\author{
OLEH: \\ SITI FATIMAH MUTIA SARI ${ }^{1}$, BINAHAYATI ${ }^{2}$, BUDI MUHAMMAD T ${ }^{3}$ \\ 1. Mahasiswa Program Studi Sarjana (S-1) Kesejahteraan Sosial Fakultas Ilmu Sosial dan Ilmu Politik Universitas Padjadjaran \\ 2. Pusat Studi Kesejahteraan Anak dan Keluarga Fakultas Ilmu Sosial dan Ilmu Politik Universitas Padjadjaran \\ 3. Departemen Kesejahteraan Sosial Fakultas Ilmu Sosial dan Ilmu Politik Universitas Padjadjaran \\ Email: \\ ( $\underline{\text { sitifms25@gmail.com; titirusyidi06@gmail.com; budi taftazani@yahoo.com ) }}$
}

\begin{abstract}
ABSTRAK
Anak berkebutuhan khusus merupakan anak yang dilahirkan dengan kebutuhan-kebutuhan khusus yang berbeda dari manusia pada umumnya sehingga membutuhkan pelayanan khusus. Seseorang dengan memiliki hambatan kecerdasan sudah dipastikan bahwa ia adalah penyandang tunagrahita. Anak dengan tunagrahita memiliki kecenderungan kurang peduli terhadap lingkungannya, baik dalam keluarga ataupun lingkungan sekitarnya. Masyarakat pada umumnya mengenal tunagrahita sebagai retardasi mental atau terbelakang mental atau idiot. Menurut Kustawan, D. (2016) merupakan anak yang memiliki inteligensi yang signifkan berada dibawah rata-rata dan disertai dengan ketidakmampuan dalam adaptasi perilaku yang muncul dalam masa perkembangan. Ia juga mengatakan bahwa anak dengan tunagrahita mempunyai hambatan akademik yang sedemikian rupa sehingga dalam layanan pembelajarannya memerlukan modifikasi kurikulum yang sesuai dengan kebutuhan khususnya. Selaras dengan pendapat Kustawan bahwa anak dengan tunagrahita mempunyai hambatan dalam memproses pembelajaran bagi anak pada umumnya. Meskipun anak tunagrahita memiliki hambatan tersebut, tidak menutup kesempatan untuk menerima pendidikan yang layak dan tepat baik di rumah dan khususnya di sekolah. Agar anak dengan tunagrahita memiliki masa depan yang cerah, sama seperti anak pada umumnya.
\end{abstract}

Kata Kunci : Anak Berkebutuhan Khusus, Tunagrahita, dan Pendidikan.

\begin{abstract}
ABSTRACK
Children with special needs are children born with special needs that are different from humans in general and require special services. A person with a barrier of intelligence has been assured that he is a person with a disability. Children with tunagrahita have a tendency to care less about the environment, either in the family or the surrounding environment. Society generally recognizes tunagrahita as mental retardation or mental retardation or idiot. According to Kustawan, D. (2016) is a child who has a significant intelligence below average and accompanied by an inability to adapt the behavior that emerged in the development period. He also said that children with tunagrahita have academic obstacles such that in the learning service requires modification of curriculum that suits their particular needs. In line with the opinion of Kustawan that children with tunagrahita have barriers in processing learning for children in general. Although child retardation has these barriers, it does not close the opportunity to receive proper and proper education both at home and especially at school. In order for a child with tunagrahita to have a bright future, just like a child in general.
\end{abstract}

Keywords : Children with special needs, Tunagrahita, and education. 


\section{Pendahuluan}

Sekolah merupakan sebuah tempat yang dijadikan sebagai sarana dalam suatu pembelajaran untuk anak. Selaras dengan pemaparan oleh Sunarto (1993) dalam Abdullah (2011) pada saat ini kata sekolah telah berubah artinya menjadi bangunan atau lembaga untuk belajar dan mengajar serta tempat memberi dan menerima pelajaran. Pada prosesnya, sekolah diciptakan untuk memberikan pengajaran kepada anak (murid) dengan pengawasan beberapa pendidik (guru) dengan tujuan tertentu. Tujuan tersebut untuk membentuk anak (murid) agar mengalami kemajuan dan perkembangan pengetahuan. Perkembangan dari pengetahuan tersebut diperoleh dengan proses pembelajaran.

Berdasarkan pemaparan Edzioni (1964) dalam Robinson (1986) mengemukakan bahwa sekolah telah "dengan sengaja diciptakan" dalam arti bahwa pada tertentu telah diambil sebuah keputusan untuk mendirikan sekolah guna memudahkan pengajaran yang sangat beraneka ragam. Berkaca dengan pemaparan sebelumnya, sekolah merupakan sebuah sistem yang saling terkait di dalamnya, ada pihak sebagai pengajar, ada pihak yang menerima pengajaran, adapula pihak yang membuat sekoalh terlihat selalu bersih. Hal ini menunjukan bahwa saat sekolah "dengan sengaja diciptakan" maka segala sesuatu yang ada di dalamnya sudah terkondisikan dengan baik. Mulai dari tenaga pendidik yang berkompeten di bidangnya, sistem pembelajaran yang sesuai dengan pihak yang menerima pengajaran dalam hal ini anak murid, dan semua fasilitas sekolah yang mendukung kedua pihak tersebut. Terlepas dari tingkatan sekolah yang beragam mulai dari Sekolah Dasar (SD), Sekolah Menengah Pertama (SMP), Sekolah Menengah Atas (SMA), baik sekolah negeri ataupun swasta.

Merujuk pada Undang-undang nomor 20 tahun 2003 tentang Sistem Pendidikan Nasional pada pasal 15 yang berbunyi "jenis pendidikan mencakup pendidikan umum, kejuruan, akademik, profesi, vokasi, keagamaan, dan khusus". Melihat dari penjelasan tersebut, Indonesia sudah memperhatikan orang dengan berkebutuhan khusus dalam mendapatkan pendidikan yang setara dengan adanya peraturan tersebut. Indonesia dalam kategori sekolah untuk orang dengan berkebutuhan khusus terdapat sekolah inklusi dan sekolah luar biasa. Menurut data statistik sekolah luar biasa (SLB) 2015/2016 yang dikeluarkan oleh Kementerian Pendidikan dan Kebudayaan, terdapat total 1.546 sekolah luar biasa baik negeri atau swasta ${ }^{1}$.

Anak berkebutuhan khusus adalah anak yang dalam proses pertumbuhan atau perkembangan mengalami kelainan atau penyimpangan fisik mental-intelektual sosial atau emosional dibanding dengan anak-anak lain seusianya, sehingga mereka memerlukan pelayanan khusus (Darmawanti dan Jannah, 2004: 15). Meskipun anak termasuk kedalam kategori anak berkebutuhan khusus, tetapi memiliki hak yang sama dengan anak pada umumnya. Anak berkebutuhan khusus berhak mendapatkan kasih sayang yang sama dari kedua orang tuanya, perlakuan khusus sesuai kategori yang dialaminya, serta mendapatkan mendapatkan pendidikan yang layak dan memenuhi setiap kebutuhannya. Sebagaimana diketahui bahwa anak dengan berkebutuhan khusus memiliki kebutuhankebutuhan khusus sesuai dengan kategorinya yang harus terpenuhi, baik di rumah atau bahkan di sekolah terlebih bagi anak tunagrahita.

Ada pula penelitian sebelumnya yang dilakukan oleh Muhammad 'Ainul Yaqin pada tahun 2015 mengenai Peran Orang Tua dalam Menanamkan Akhlak pada Anak Tunagrahita di Sekolah Luar Biasa (SLB) Negeri Semarang (perspektif bimbingan islam). Dalam penelitian tersebut menjelaskan bahwa dengan segala kendala sikap dan perilaku dari anak tunagrahita, orang tua tetap memiliki peran dalam pembentukan sikap, perilaku dan karakter di dalam rumah. Sejalan dengan penelitian tersebut, peneliti beranggapan bahwa selain peran orang tua, ada pula peran sekolah dalam pemenuhan kebutuhan perkembangan anak tunagrahita.

Karena keterlambatan dalam perkembangan kecerdasannya, siswa tunagrahita akan mengalami berbagai hambatan dalam upaya memenuhi kebutuhan-kebutuhan tersebut, bahkan diantara mereka ada yang mencapai sebagaian atau kurang, tergantung pada berat ringannya hambatan yang dimiliki anak serta perhatian yang diberikan oleh lingkungannya. Menurut Witmer \& Kotinsky (Frampton \& Gail, 1955: 117-119)

\footnotetext{
${ }^{1}$ Kementerian Pendidikan dan Kebudayaan. 2016.

Statistik Sekolah Luar Biasa (SLB) 2015/2016.
} 


\begin{tabular}{|l|l|l|l|l|}
\hline Jurnal Penelitian \& PKM & Juli 2017 & Vol 4, No: 2 & Hal: $129-389$ & ISSN \\
\hline
\end{tabular}

menjabarkan kedelapan kebutuhan tersebut, yaitu²

1. Perasaan terjamin kebutuhannya akan terpenuhi (The Sense of Trust)

2. Perasaan Berwenang mengatur diri (The Sense of Autonomy)

3. Perasaan dapat berbuat menurut prakarsa sendiri (The Sense of Intiative)

4. Perasaan puas telah melaksanakan tugas (The Sense of Duty and Accomplisment)

5. Perasaan bangga atas identitas diri (The Sense of Identity)

6. Perasaan Keakraban (The Sense of Intimacy)

7. Perasaan Keorangtuaan (The Parental Sense)

8. Perasaan Integritas (Integrity Sense)

Selain kedelapan kebutuhan khusus yang telah dijabarkan sebelumnya, menurut Astati adapula kebutuhan anak tunagrahita secara garis besar dapat dikelompokan menjadi kebutuhan fisik dan kebutuhan kejiwaan. ${ }^{3}$ Kebutuhan-kebutuhan tersebut merupakan hal yang cukup penting bagi anak penyandang tunagrahita, agar anak tersebut dapat tumbuh dan berkembang secara normal dengan bantuan setiap orang disekitarnya.

\section{Metode}

\section{Metode penelitian}

Metode penelitian ini menggunakan penelitian kualitatif deskriptif. Metode deskriptif ini bertujuan untuk memecahkan masalah dari data yang ada dan berkembang sampai sekarang, berusaha menggambarkan apa adanya objek yang di teliti, menuturkan dan menafsirkan data yang ada. Adapun peneliti disini adalah menggambarkan secara sistematis, faktual, dan akurat mengenai fakta - fakta penelitian, pemenuhan kebutuhan khusus bagi siswa penyandang tunagrahita sedang di Sekolah Luar Biasa Negeri Purwakarta.

\section{Teknik Pengumpulan Data}

Teknik yang penulis lakukan dalam rangka mencari dan mengumpulkan data adalah dengan cara :

\footnotetext{
${ }^{2}$ Astati. Anak dengan Hambatan Perkembangan. Hal 70-72
}

a. Observasi kelapangan penelitian, teknik ini dilakukan untuk memperoleh data primer, kemudian mengumpulkan data-data dari refensi yang berkaitan dengan penelitian.

b. Wawancara, teknik ini digunakan untuk mengumpulkan data dengan mengajukan pertanyaan secara langsung kepada responden.

c. Studi dokumentasi, teknik ini bertujuan untuk mendokumentasikan hal-hal yang perlu di dokumentasikan.

\section{Hasil dan Pembahasan \\ Hak Anak Disabilitas atas Pendidikan}

Hak dari anak penyandang disabilitas menjadi sorotan penting pada setiap negaranya, termasuk Indonesia. Bahkan bukan hanya di Indonesia saja, melainkan pada tingkat duniapun menjadi sorotan khusus. Karena orang dengan disabilitas termasuk anak didalamnya berhak mendapatkan perlindungan dari negara terkait kehidupannya.Telah dirumuskan mengenai HakHak Penyandang Disabilitas oleh Perserikatan Bangsa-Bangsa atau PBB pada tahun 2006 dan disetujui oleh Indonesia. Dalam Konvensi Hak-hak Penyandang Disabilitas ini mencakup berbagai hal dalam kehidupan bernegara dan menjamin kesetaraan bagi penyandang disabilitas.

Pada pasal 24 dalam Konvensi Hak-hak Penyandang Disabilitas mengenai Pendidikan, sebagai berikut :

\section{Pasal 24}

\section{Pendidikan}

1. Negara-negara pihak mengakui hak penyandang disabilitas atas penddikan. Dalam rangka memenuhi hak ini tanpa diskriminasi dan berdasarkan kesempatan yang sama, Negara-negara pihak wajib menjamin sistem pendidikan yang bersifat inklusif pada setiap tingkatan dan pembelajaran seumur hidup yang terarah kepada:

a. Pengembangan seutuhnya potensi diri dan rasa martabat dan harga diri serta penguatan penghormatan atas hak asasi manusia, kebebasan

\footnotetext{
${ }^{3}$ Astati. Anak dengan Hambatan Perkembangan. Hal 72
} 
fundamental dan keanekaragaman manusia;

b. Pengembangkan atas kepribadian, bakat, dan kreatfitas, serta kemampuan mental dan fisik dari penyandang disabilitas hingga mencapai potensi sepenuhnya;

c. Memungkinkan penyandang disabilitas untuk berpartisipasi secara efektif dalam masyarakat umum.

2. Dalam memenuhi hak tersebut, NegaraNegara Pihak wajib menjamin:

a. Penyandang disabiltas tidak dikecualikan dari sistem pendidikan umum berdasarkan alasan disabilitas, dan bahwa penyandang disabilitas anak tidak dikecualikan dari pendidikan dasar wajib dan gratis atau dari pendidikan lanjutan berdasarkan alasan disabilitas;

b. Penyandang disabilitas dapat mengakses pendidikan dasar dan lanjuran yang inklusif, berkualitas dan gratis atas dasar kesamaan dengan orang lain di dalam masyarakat yang mereka tinggali;

c. Penyediaan akomodasi yang beralasan bagi kebutuhan individual tersebut;

d. Penyandang disabilitas menerima dukungan yang dibutuhkan, di dalam sistem pendidikan umum, guna memfasilitasi pendidikan yang efektif;

e. Sarana pendukung individu yang efektif tersedia di lingkungan yang dapat memaksimalkan pengembangan akademis dan sosial, konsisten dengan tujuan untuk penyertaan penuh.

3. Negara-Negara Pihak wajib memungkinkan penyandang disabilitas untuk mempelajarikehdupan dan keahlian pengembangan sosial untuk memfaslitasi partsipasi penuh dan setara dalam penddikan dan sebagai anggota dari masyarakat. Untuk mencapai tujuan ini, Negara-Negara Pihak wajb mengambil langkah-langkah yang tepat, termasuk:

a. Memfasilitasi pelajaran Braile, tulisan alternatif, bentuk, sarana dan format komunkasi yang bersifat augmentatif dan alternatif serta orientasi dan keteramplan mobiltas, serta memfasilitasi sistem ddukungan dan mentoring sesama penyandang dsabiltas;

b. Memfasilitasi pelajaran bahasa isyarat dan pemajuan dentitas Inguistik dar komunikasi tuna rungu;

c. Menjamin bahwa pendidikan orangorang, termasuk anak-anak, yang tuna netrea, tuna rungu atau tuna netrarungu, disampaikan dalam bahasa, bentuk dan sarana komunikas yang paling cocok bagi individu dan di dalam Ingkungan yang memaksimalkan pengembangan akademis dan sosial.

4. Dalam rangka menjamin pemenuhan hak tersebut, Negara-Negara Pihak wajib mengambil langkah yang tepat untuk mempekerjakan guru-guru, termasuk guru dengan disabilitas, yang memiliki kualifkasi dalam bahasa isyarat dan/atau Braile, dan untuk melatih para profesional dan staf yang bekerja dalam berbagai tingkatan pendidikan. Pelatihan akan mengikut sertakan kesadaran mengenai disabilitas dan penggunaan bentuksarana dan format komunikasi serta teknik dan bahan pendidikan yang bersifat augmentatif dan alternatif guna mendukung penyandang disabilitas.

5. Negara-Negara pihak wajib menjamin bahwa penyandang disabilitas dapat mengakses pendidikan umum menengah pelathan kejuruan, pendidikan dewasa, dan lain. Untuk mencapa tujuan ini, negara-negara pihak wajib menjamin bahwa akomodasi yang beralasan bagi penyandang disabilitas. ${ }^{4}$

Berdasarkan pemaparan mengenai hak-hak penyandang disabilitas, sudah sangat jelas bahwa Negara menjamin kebutuhan setiap penyandang disabilitas sesuai dengan kategorinya. Negara pun tidak melakukan diskriminasi terhadap berbagai aspek kehidupan dari penyandang disabilitas.

\section{Tunagrahta}

Tunagrahita (seseorang yang memiliki hambatan kecerdasan) menurut Kustawan, D. (2016) merupakan anak yang memiliki inteligensi yang signifkan berada dibawah rata-rata dan disertai dengan ketidakmampuan dalam adaptasi perilaku yang muncul dalam masa perkembangan.

\footnotetext{
${ }^{4}$ Terjemahan Konvensi Hak-hak Penyandang

Disabilitas oleh Perserikatan Bangsa-Bangsa (PBB)

Pasal 24 tentang Pendidikan
} 
Ia juga mengatakan bahwa anak dengan tunagrahita mempunyai hambatan akademik yang sedemikian rupa sehingga dalam layanan pembelajarannya memerlukan modifikasi kurikulum yang sesuai dengan kebutuhan khususnya.

Masyarakat pada umumnya mengenal tunagrahita sebagai retardasi mental atau terbelakang mental atau idiot. Rachmayana, D. (2016) mengemukakakan bahwa tunagrahita berarti suatu keadaan yang ditandai dengan fungsi kecerdasan umum yang berada dibawah rata-rata disertai dengan berkurangnya kemampuan untuk menyesuaikan diri (berperilaku adaptif), yang mulai timbul sebelum usia 18 tahun. Ia juga mengatakan bahwa orang-orang secara mental mengalami keterbelakangan, memiliki perkembangan kecerdasan (IQ) ${ }^{5}$ yang lebih rendah dan mengalami kesulitan dalam proses belajar serta adaptasi sosial.

\section{Kebutuhan Khusus Tunagrahita}

Menurut Witmer \& Kotinsky (Frampton \& Gail, 1955: 117-119) menjabarkan kedelapan kebutuhan tersebut, yaitu ${ }^{6}$ :

1. Perasaan terjamin kebutuhannya akan terpenuhi (The Sense of Trust)

2. Perasaan Berwenang mengatur diri (The Sense of Autonomy)

3. Perasaan dapat berbuat menurut prakarsa sendiri (The Sense of Intiative)

4. Perasaan puas telah melaksanakan tugas (The Sense of Duty and Accomplisment)

5. Perasaan bangga atas identitas diri (The Sense of Identity)

6. Perasaan Keakraban (The Sense of Intimacy)

7. Perasaan Keorangtuaan (The Parental Sense)

8. Perasaan Integritas (Integrity Sense)

Komponen kepribadian yang sehat adalah rasa integritas. Ni sangat bergantung dari semua yang telah diterangkan sebelumnya. Jika pengalaman individu sepanjang hidupnya salah, maka ia tdak

\footnotetext{
${ }^{5} \mathrm{IQ}=$ Intellegent Quentiont (ukuran kecerdasan)
}

akan bisa menerima tuntutan (lingkungan) kehidupannya. Salah satu tujuan dari pendidikan khusus seharusnya mempersiapkan anak berkelainan untuk menyempurnakan rasa integritasnya.

\section{Simpulan dan Saran}

Berdasarkan dari beberapa literatur yang sudah dipaparkan, penulis meyadari betul bahwa anak berkebutuhan khusus memiliki hak yang sama, khususnya tunagrahita. Hak yang sama dalam berbagai hal, termasuk mendapatkan pendidikan yang layak. Pendidikan secara formal ataupun nonformal. Merekapun memiliki hak untuk mendapatkan semua fasilitas yang diberikan oleh negara dengan tanpa dibedakan.

\section{Daftar Pustaka}

Books

Abdullah, H. (2011). Sosiologi Pendidikan : Individu, Masyarakat, dan Pendidikan. Jakarta: Rajawali Pers.

Darmawanti, Ira dan M. Jannah. 2004. Tumbuh Kembang Anak Usia Dini dan Reaksi Dini pada Anak Berkebutuhan Khusus. Surabaya: Insight Indonesia.

Kustawan, D. (2016). Bimbingan dan Konseling bagi Anak Berkebutuhan Khusus. Jakarta Timur: PT. LUXIMA METRO MEDIA.

Lexy J. Moleong. 1999. Metodologi Penelitian Kualitatif. Bandung: PT. Remaja Rosdakarya.

Rachmayana, D. (2016). Menuju Anak Masa Depan yang Inklusif. Jakarta Timur: PT. LUXIMA METRO MEDIA.

Raharjo, ST. 2015. Assessment untuk Praktik Pekerjaan Sosial dan Kesejahteraan Sosial. Bandung: Unpad Press 2015. Dasar Pengetahuan Pekerjaan Sosial. Bandung: Unpad Press.

\footnotetext{
${ }^{6}$ Astati. Anak dengan Hambatan Perkembangan. Hal 70-72
} 


\begin{tabular}{|c|c|c|c|c|}
\hline Jurnal Penelitian \& PKM & Juli 2017 & Vol 4, No: 2 & Hal: $129-389$ & $\begin{array}{c}\text { ISSN } \\
2442-448 X(p), 2581-1126(e)\end{array}$ \\
\hline
\end{tabular}

2015. Keterampilan Pekerjaan Sosial: Dasar-dasar. Bandung, Unpad Press.

Robinson, P. (1986). Beberapa Perspektif Sosiologi Pendidikan. Jakarta: Rajawali.

Sugiyono. (2009). Metode Penelitian Kuantitatif dan Kualitatif Dan $R \& D$. Bandung : Alfabeta.

Suparno. (2007). Pendidikan Anak Berkebutuhan Khusus. Direktorat Jenderal Pendidikan Tinggi Departemen Pendidikan Nasional.

Kementerian Kesehatan RI. (2014) Situasi Penyandang Disabilitas. Buletn Disabilitas

\section{Website}

Arafat, MA. (2009). Retriever April 16, 2017, from UIN Surabaya: digilib.uinsby.ac.id
Arjuna, B. (2014). Retrieved April 17, 2017, from UIN Sunan Gunung Djati: digilib.uinsgd.ac.id

Astati. Anak dengan Hambatan Perkembangan. Retrieved April 16, 2017, from UPI web site : file.upi.edu

Kementerian Pendidikan dan Kebudayaan. 2016. Statistik Sekolah Luar Biasa (SLB) 2015/2016

Wikipedia. (n.d.). Wikipedia. Retrieved April 17, 2017, from Wikipedia web site: id.m.wikipedia.org

\section{Peraturan}

Terjemahan Konvensi Hak-hak Penyandang Disabilitas oleh Perserikatan Bangsa-Bangsa (PBB) 